\title{
A successful ovarian cancer case
}

Andrew Hague BA (Hons). Dip M.

President of CellSonic Limited

Corresponding Author: Andrew Hague, President of CellSonic Limited.

Received date: May 19, 2021; Accepted date: June 07, 2021; Published date: June 09, 2021

Citation: Andrew Hague. (2021) A successful ovarian cancer case. J. Cancer Research and Cellular Therapeutics. 5(3); Doi: 10.31579/26401053/085

Copyright: (C) 2021 Andrew Hague, This is an open access article distributed under the Creative Commons Attribution License, which permits unrestricted use, distribution, and reproduction in any medium, provided the original work is properly cited.

\begin{abstract}
A lady discovered she had ovarian cancer in 2016 and was treated by CellSonic. The tumour remained big and had to be surgically removed after the cancer was stopped. Since then, cancerdiagnostics have progressed and the electrical properties can now be easily detected allowing CellSonic to advance from stopping cancer in a patient to stopping cancer in a population.

The patient is well and has approved this article.

Keywords: ovarian cancer; cellsonic; cell voltage; sapiens shield; sundar raman
\end{abstract}

This report is based on information passed to me by Sundar Raman [1] in Pune in India who treated the patient, Hema Bauskar, with a CellSonic VIPP machine. Hema has agreed to be identified and hermedical details made public. It is important to remember that it was Sundar with his colleague, Manoj Borad, who treated the first cancer patient with CellSonic, Amir Hossein from Bangladesh in November 2016 for prostate cancer and he is alive today.

\section{Patient Details...}

Patient Name: Mrs.HemaBhauskar

Patient Age: 53 years

Consulting Dodor:Dr. Sarvesh Kulkarni

Case History: Patient suffering from ovarian cancer with confirmatory testsdone in first week of December 2016.

For many years, Mrs. Hema has been under the care of her family doctor, Dr.

Sarvesh Kulkarni who is an Ayurvedic Doctor.
To include all the details of the case so that you, the reader, can appreciate what was done and achieved, I am presenting the findings as they were received. Sundar Raman took great pride in putting the information in a form that is easy to comprehend so I am copying it straight into this article so that you see what I saw. Note the dates. The first report was at the end of 2016 and runsinto early 2017 and then nothing more until April 2021. My observations will be made at the end after the findings.

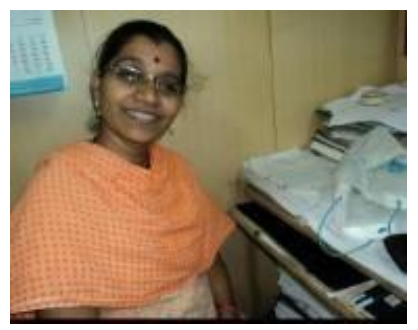

The indications were probably first noticed around first week of November 2016 when Mrs. Hema's stomach suddenly became bloated and increasing insize. She had a lot of pain and all her movements were very restricted. By end of November she was nearly bed ridden with immense pain. Also there was a hardness felt at two locations on the stomach matching to area of the tumor which was later confirmed by tests. The tumor growth was fast and painful.

The news of cancer came as a shock to Mrs. Hema. She was advised to go forsurgical removal of the cancer tumor along with two sessions of Chemo treatment. Mrs Hema admits she thought she was going to die. 


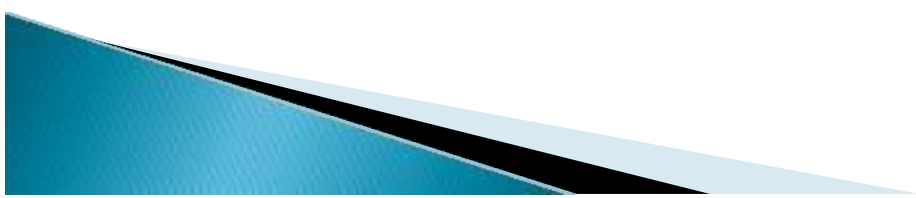

In the second week of December she contacted CellSonic India to find a cure without surgery or chemotherapy. After more than a week's discussion it was agreed to start the Cellsonic VIPP treatment on 22nd December 2016. A protocol was worked out for her treatment and up to the 28th December she has had fourVIPP treatments.

Here its worth noting that from the initial depression phase, Mrs.Hema haschanged her complete outlook and approach towards this disease and decided to take it head on and fight it out rather than allowing the cancer to get the better of her. With all the discomfort and pain, she made a $500 \mathrm{~km}$ bus ride thereand back to visit her village.

She has now resumed work and started going to the office at the department of education and is doing her regular household work without any problem.

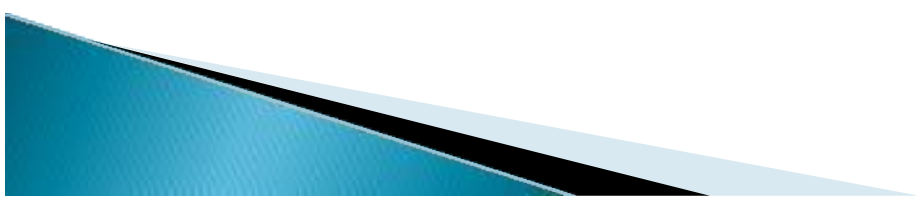

\section{$28^{\text {th }}$ December 2016}

Just back home after treatment of Mrs.Hema. She is looking fine.

Today she had been to Dr.Sarvesh for a checkup. She told me that the doctor lookedmuch more relaxedcompared to the last checkupwhen he could hardly believe what he was seeing and lookedand

Sounded very tense. Now he accepts that there is an improvement.

Also Mrs. Hema told me that after the VIPPtreatment she feels

Relaxed and energetic. She has gone back to her old habit of reading for an hour before falling to sleep Thisis not a surprise to us as we know that the VIPP treatment has a therapeutic effect .She has got the feel good factor and therefore at this stage we can confidently say that she is on the path of curing which I am sure any oncologist would not say even aftertwo or threetreatments of Chemo. I did ask her if she felt that she has been cured or not for which she replied that she feels much betterthan she felt two weeksago but would like to see the bloat of the stomach go to confidently say thashe has been cured.

Probably we will do asonography scan next week to check on thesize of thetumour.
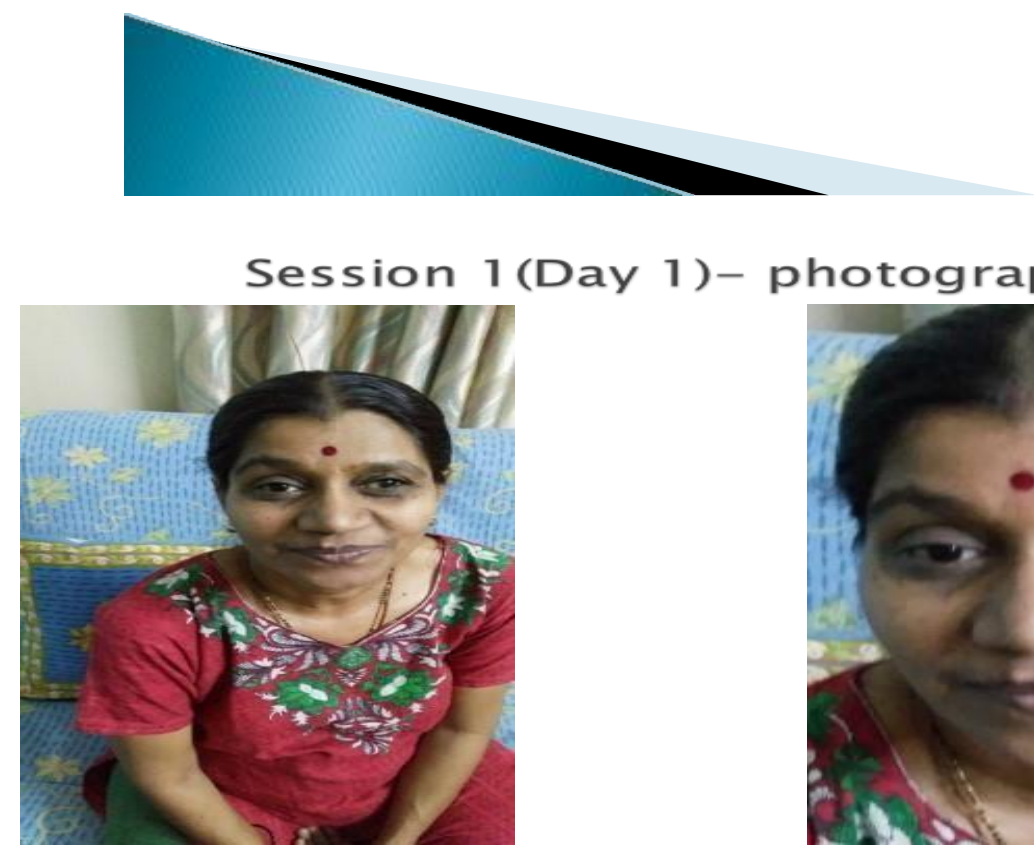

1 (Day 1)- photograph
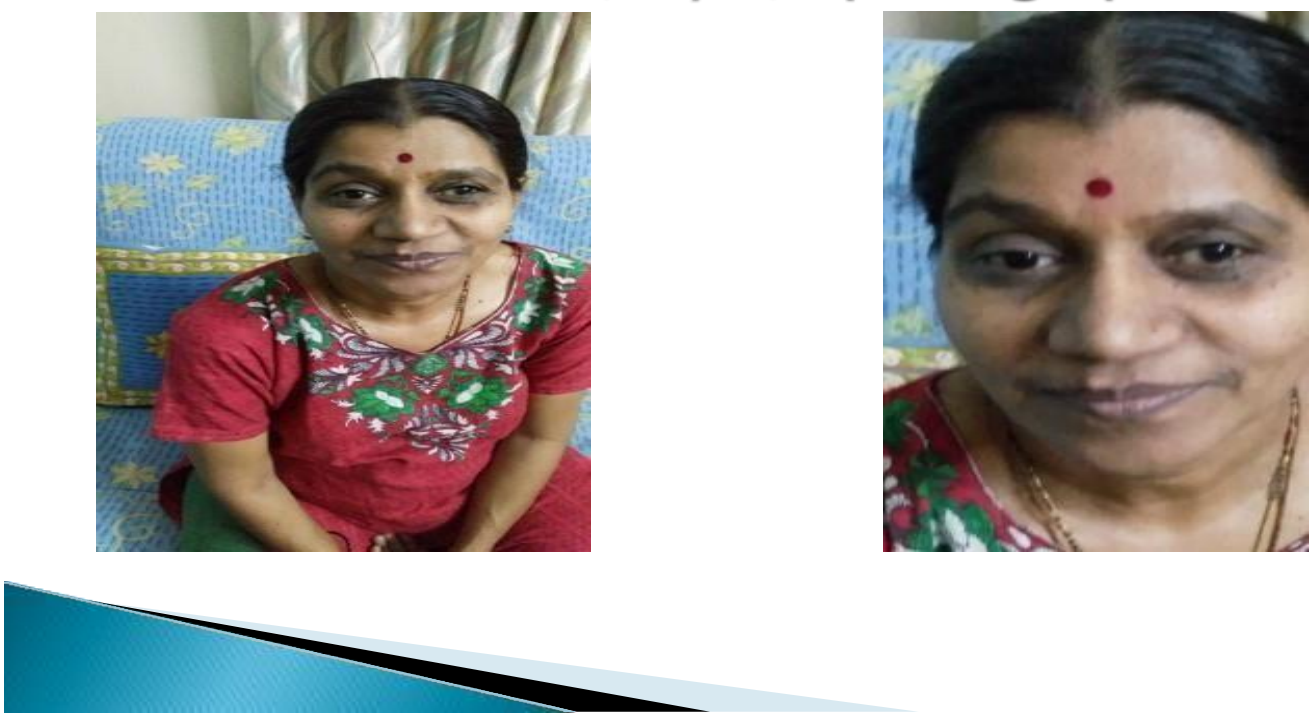


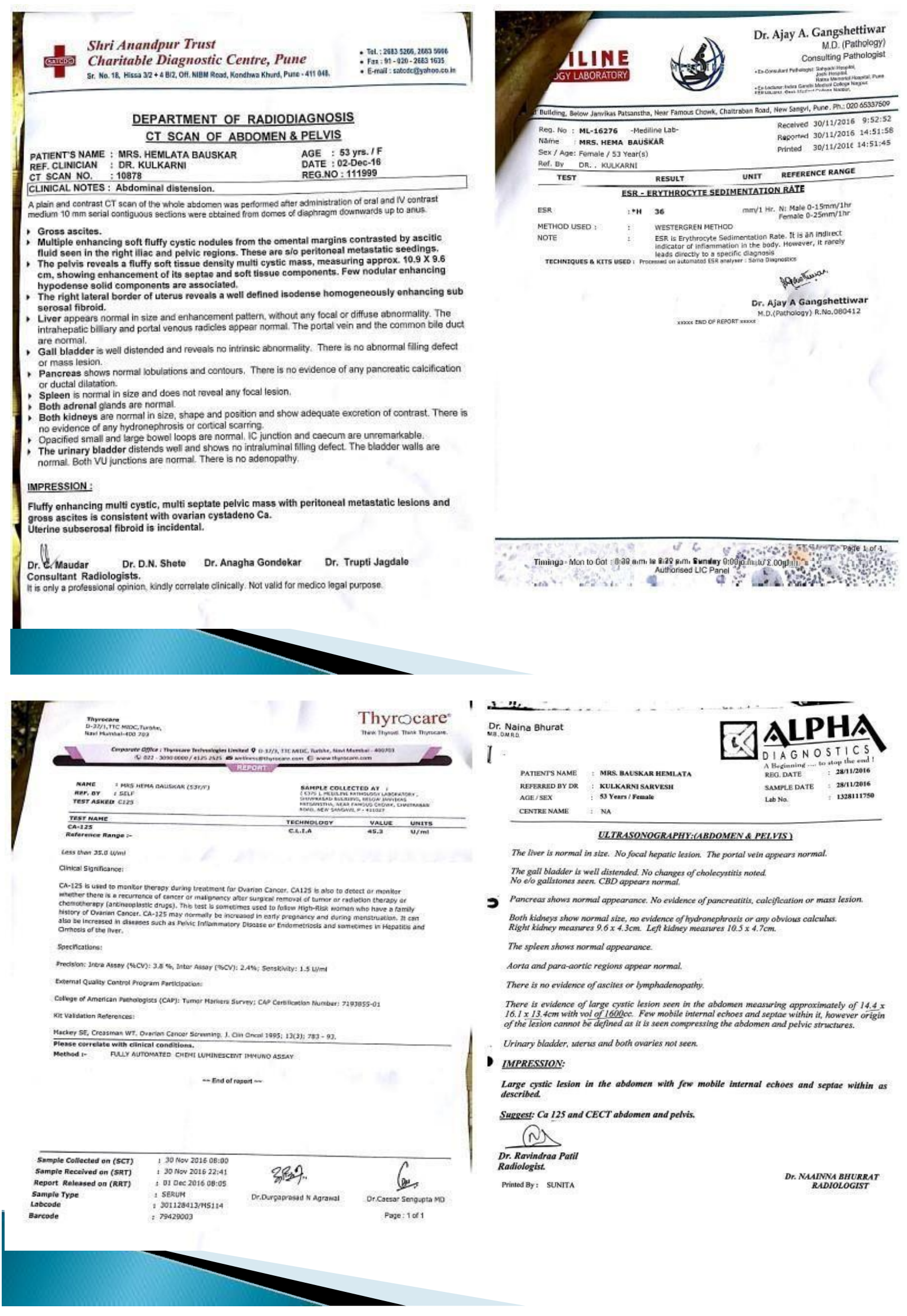




\section{Summary as on date $28^{\text {th }}$ December 2016}

Treatment started on $22^{\text {nd }}$ 2900 pulses at EL 4

Total sessions completed as on 28 December 2016-4

\section{No Drugs....no side effects Lowest cost of cure}

\section{Amputation is "NOT" healing}

Wed 26/04/2017Dear Andrew,

Good Morning. Attached are the latest test reports of Mrs. Hema conducted this week.

As per my understanding of the CT scan, there is a very slight increase in the tumour size or ratherwe can say that it remains the same. The CA 125 level has increased.
Another major development is that she is experiencing a paralytic type attack on her left side. Herleft side of the face is not responding and also the left arm.

Her husband and brother have requested me to start the Cellsonic VIPP treatment immediately asthey feel she was in a much better condition when being treated with VIPP.

Request your advice on how to proceed further.best regards Sundar

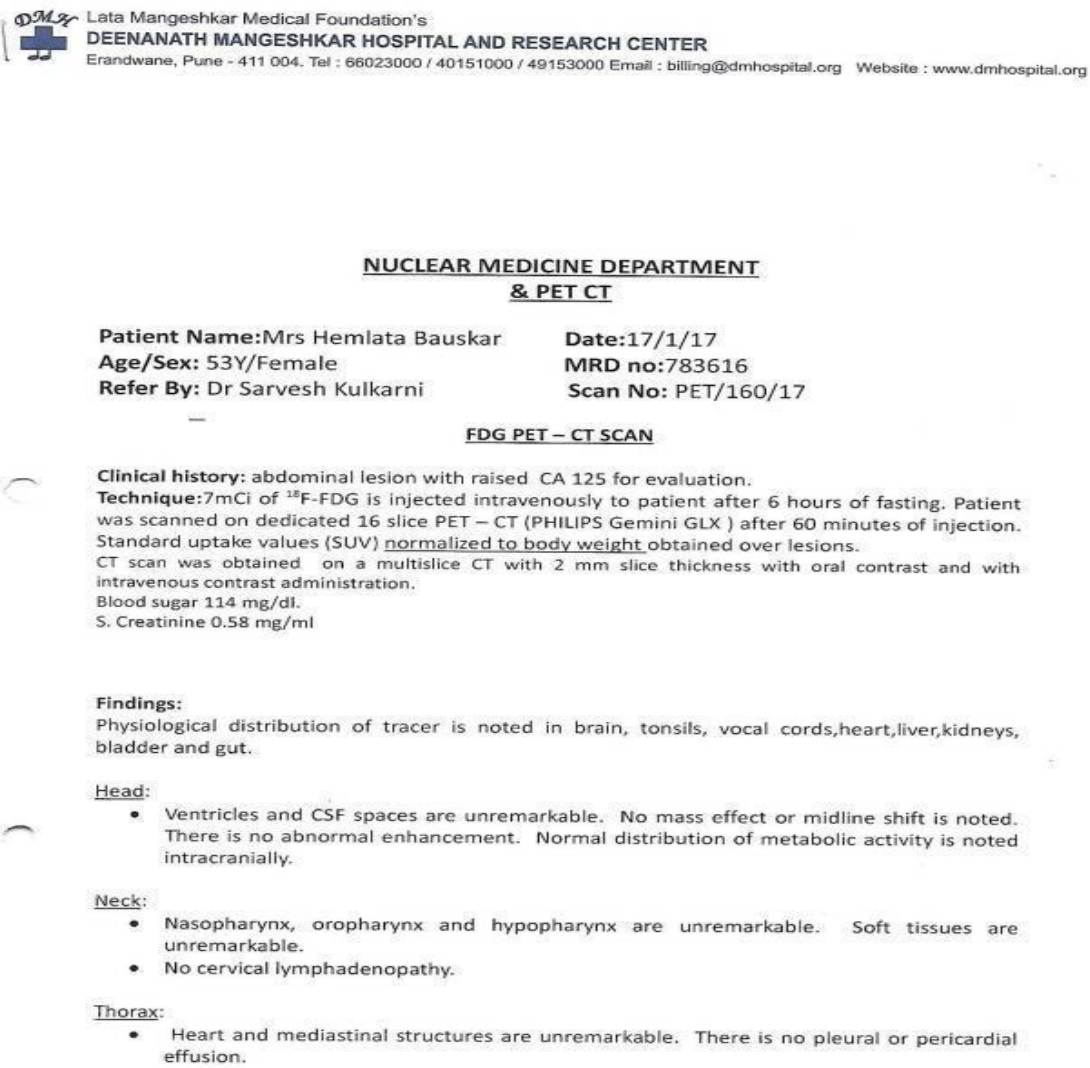


Lata Mangeshkar Medical Foundation's

DEENANATH MANGESHKAR HOSPITAL AND RESEARCH CENTER

Erandwane, Pune - 411 004. Tel : 66023000/40151000/49153000 Email : billing@dmhospital.org Website : www.dmhospital.org

- Tiny soft tissue dense nodule is noted in right upper lobe posterior segment without any FDG uptake. Too small to characterize.

- No mediastinal lymphadenopathy.

Abdomen \& pelvis:

- Liver, Spleen,gallbladder, pancreas, kidneys and adrenals are unremarkable.

- Large hypodense predominently cystic lesion pelvi abdominal lesion is seen measuring $21 \times 10.2 \times 17.8 \mathrm{~cm}$. The lesion shows minimal peripheral enhancement with avid FDG uptake. No septations / calcification noted in the lesion. Multiple soft tissue dense Fdg avid csolid components are noted involving pelvic part of the lesion. Maximum area of

1. FDG uptake measures approximately $40 \times 26 \mathrm{~mm} \mathrm{~mm}$ SUV 7.02 . The lesion is seen inferiorly extending to left adnexa. Right ovary is normal, Left ovary is not seen separate.

- no retroperitoneal and pelvic lymphadenopathy.

- No abnormal FDG avid omental lesion.

Musculoskeletal:

- degenerative changes noted in spine.

\section{COMMENTS:}

53 years female with abdominal lesion with raised CA 125 for evaluation.

- Large predominantly cystic pelviabdominal lesion with hyperdense metabolically active solid component within are suggestive of primary ovarian malignancy.

- No other metabolically active disease noted elsewhere.

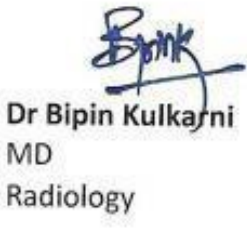

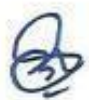

Dr Sujit Nilegaonkar MBBS, DRM, RSO

DNB Nuclear Medicine

09096076446 


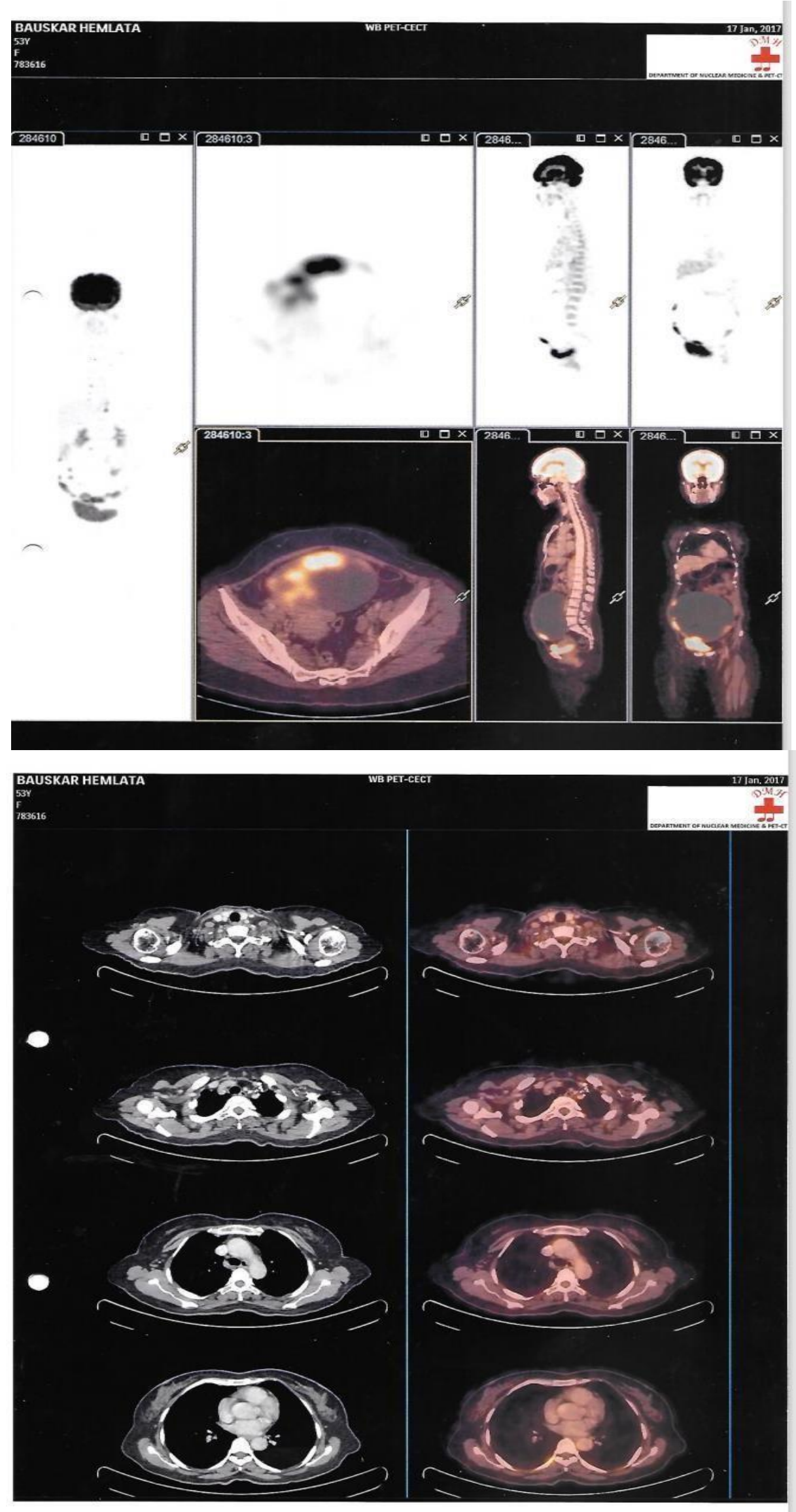



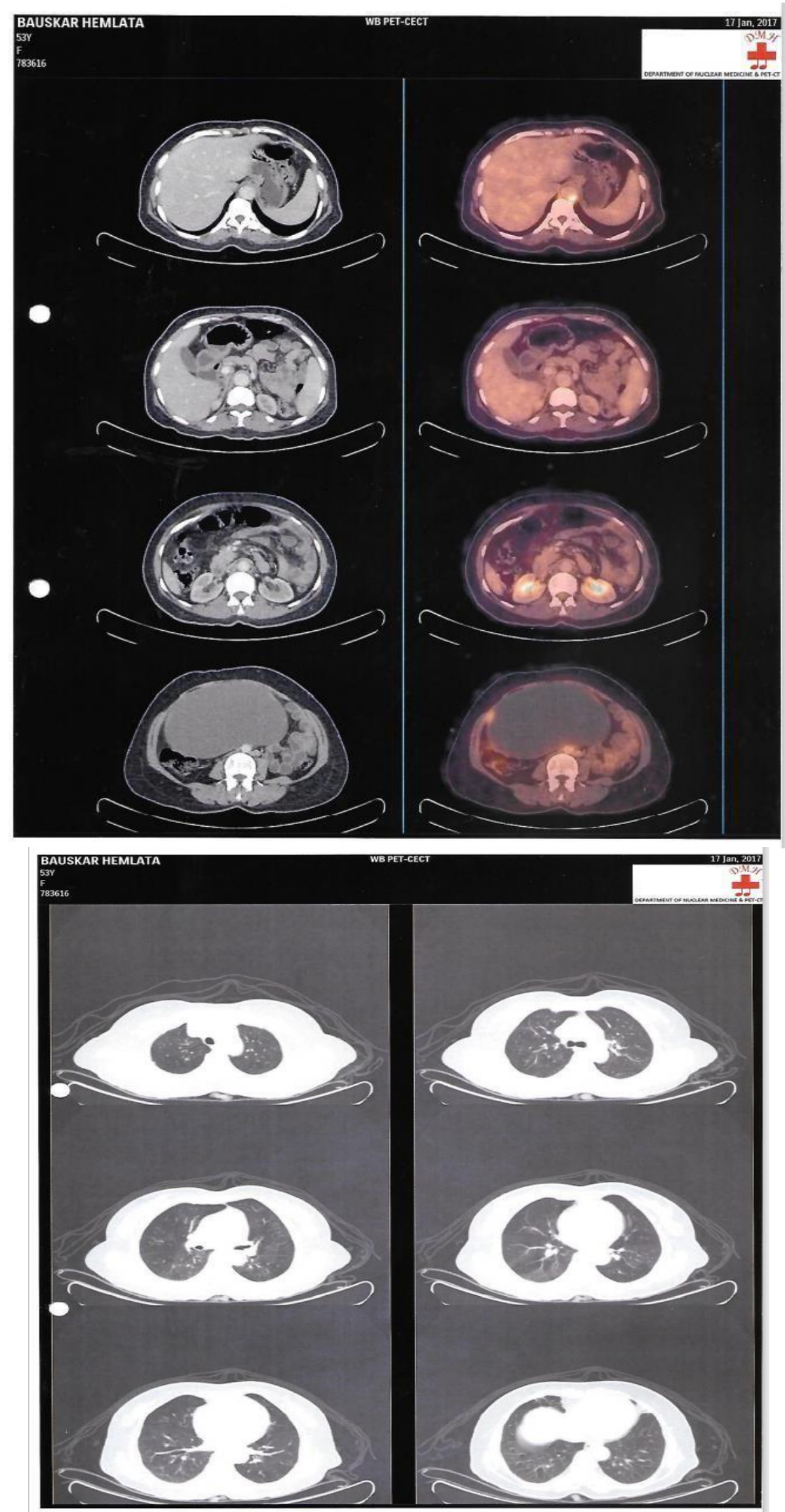

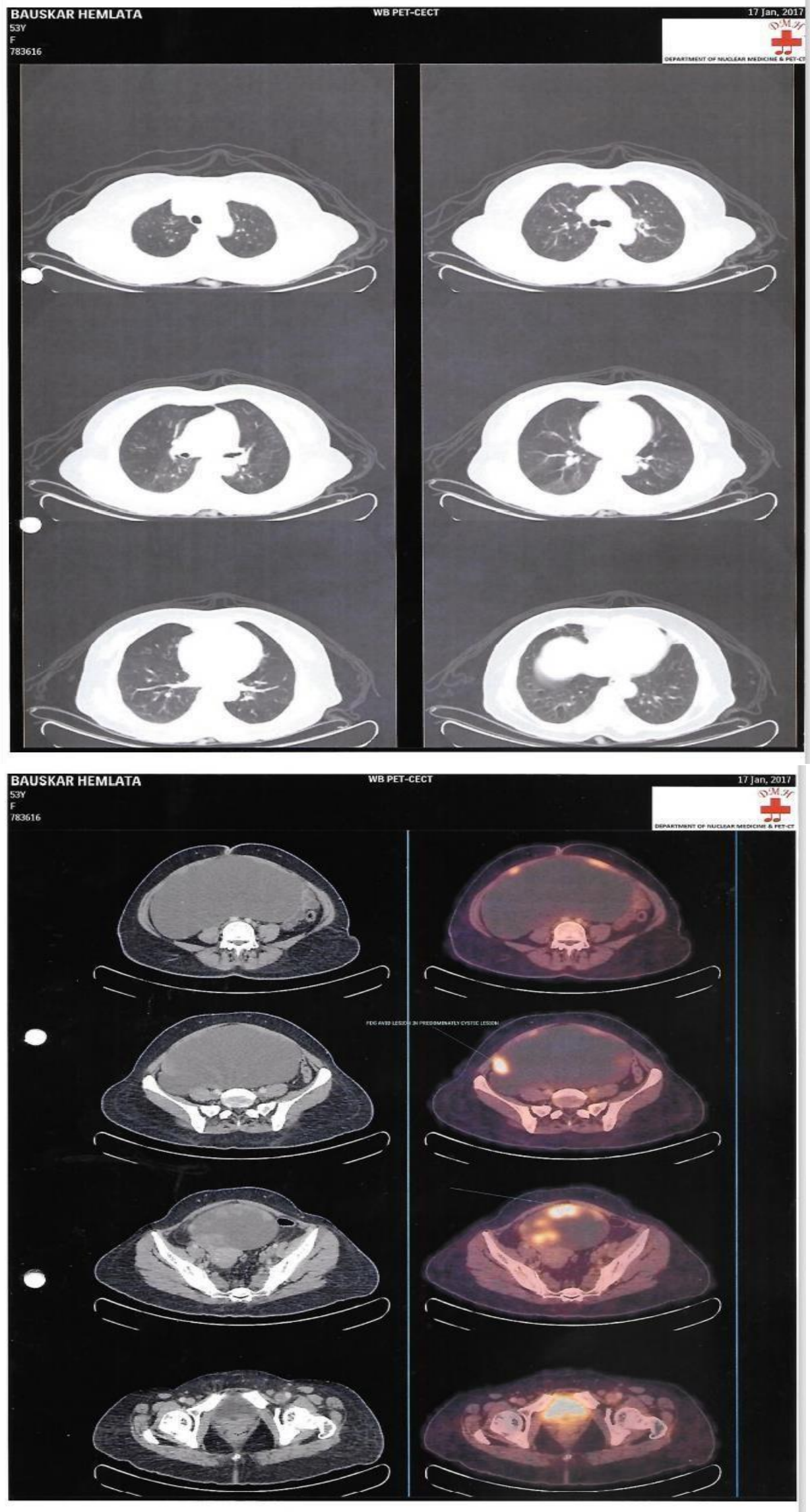
After a gap of more than four years during which time there was no mention of Hema, I received thefollowing email from Sundar:

\section{Sat 27/03/2021Hello Andrew,}

With all the not so good news of the current situation globally on the Covid 19 pandemic, there isone good news which I got last week.

Hema Bauskar you remember was diagnosed of 4th stage Ovarian cancer with her cancer tumour nearly growing to a size of a baseball and weighing $2 \mathrm{kgs}$ around 4 years back. In the initial stages ofher cancer, as you may remember, she had refused to undergo any treatment and was taking Ayurvedic treatment of Dr. Kulkarni. After a few weeks into her diagnosis she was given around 8 sessions of CellSonic by me. It was only when she was unable to bear the weight of the $2 \mathrm{~kg}$ tumourand $4 \mathrm{kgs}$ of fluid which had accumulated around the tumour that she decided to opt for surgery to Remove the tumour but there was a condition put by the doctors (the MD surgery and MD Oncologyat Dinanath Hospital Pune - I will not mention the names of the doctors) that she will need to undergo 13 sessions of chemotherapy before surgery. It was condition which had to be accepted in order to get the huge tumour surgically removed which actually looked as if she was 5 to 6 months pregnant.

After getting admitted to Dinanath Hospital and all the prescribed chemo sessions, she was operatedand the tumour surgically removed.

After her operations, she was regularly having her tests done to check for any relapse signs everythree months for the last four years.

Last week when she went to meet her Oncologist doctors with her test results, he told her that therewas no further need for her to come and consult him as she was FREE from CANCER.

Although she was confident that she had completely recovered from cancer, she wanted the doctor to himself declare it which has now happened.

Best regardsSundar

Mon 29/03/2021Hello Andrew,

Met Hema yesterday evening and passed on your greetings to her. Also told her if she could pen down her experiences till date. She said she would try but one of the side effects of the chemo we have seen is that it has affected her memory and ability to retain. Sometimes she would pick up hercell phone to call someone and then suddenly forget why she was calling this person. Also, unfortunately we did not take any pictures of her at the time of her treatment as she did not want any residual memory of those horrible times.

\section{All's well that ends well.Regards Sundar}

\section{Observations}

Clearly, Hema is cured of the stage 4 ovarian cancer. At what time did the cancer cells cease to replicate profusely further malignant cells? The chemotherapy came long after the CellSonic treatments and having seen the speed of growth of her tumour it was CellSonic that stopped the cancer, not the chemotherapy. We now know that the electrical properties of the cells determine the behaviour of the cells and that CellSonic has an electrical field as part of its pulse action. WhenSundar treated Hema in 2016, we were only thinking of pressure although we knew from other patients the effect on cancers.

The comments by Hema's family that she felt better after CellSonic is significant. This is observed in almost every treatment and not just for cancer but also the many other ailments covered by CellSonic such as wounds and physiotherapy. It needs further investigation because the likelihood is that CellSonic is anti-depressant. It has an effect on the emotions and we know that stopping cancer requires a positive mental state. In Sundar's first report he states that Hema felt positive; that is medicine. It might not be measurable but it is still science even though the direct link between causeand effect is not yet obvious to us but as we go on with more patients we shall watch for the mental shifts and I am sure we shall see a discernible pattern.

We now have better cancer diagnostics [2] that were not available to Sundar four years ago. The hospital's diagnostics saw a tumour and declared it malignant. It may have been benign after the CellSonic treatment. If it had been malignant, it would have continued the cell replication profusely but it didn't. It just sat there as a heavy lump and eventually had to be removed surgically. Whether the immune system would have dissipated the lump over time, we do not know. A smaller lump mayhave been tolerated but for Hema its size made it painful.

The mental damage Hema suffered caused by the chemotherapy is a result of ignorance at the hospital. Chemo has a success rate of $2.5 \%$ which is a failure rate of $97 \%$. In other words, chemo is total failure. ${ }^{[3]}$ Why did the surgeons insist on chemo before operating? Perhaps they thought it would stop cancer cells spreading when they cut through tissues. Before then, CellSonic had stoppedthe cancer so there were no cancer cells left to spread.

Hospital and their doctors work with lawyers standing on their shoulders. Only the lawyers benefit and they don't care about anyone else. Politicians likewise remain ignorant and get cancer as much as other people. CellSonic is steadily demonstrating that cancer is not a biochemical problem, drugshave no effect; it is an electrical problem with biophysics being the effective science. This is an area of medicine previously neglected. Biochemistry in the hands of Big Pharma has only three products: anti-biotics, vaccines and anaesthetics. All their other offerings do not work whatever claims they make.

Biophysics deal with chronic illness and are showing as low voltage areas [4]. Correct those voltagesand the chronic condition improves without drugs.

Mental diseases are also responding to electrical fields, not direct blasts of electrical current but exposure to short duration electrical fields. If the patient preferred a totally natural cure, they wouldhave to go outside during a thunderstorm, be careful not to be hit by lightning but close enough to alightning strike to receive an increase in cell voltage. Such a protocol is impossible, dangerous and inadvisable. CellSonic is safe. It is essentially what has been used by urologists for forty years to remove kidney stones on millions of patients with no side effects. CellSonic can be called a hand- held thunderstorm $[5,6]$.

To find that the cause of pain is cancer is to realise that the cancer has been multiplying for many years, maybe ten, and lay hidden until the tumours became big enough to hurt. By then, there will have been many single cancer cells migrating from the parent tumour affecting other organs even though they will be too small to show on a scan. This is a bad situation. CellSonic is taking a differentapproach.

Having improved the diagnosis of cancer, CellSonic Limited is working to diagnose and stop cancers in people before the person is aware of it. In other words, going from stopping cancer in a person tostopping cancer in a population [7].

\section{Dr Glen Halls has analysed the data on Hema and reports as follows:}

In the five months following CellSonic treatment a reversal of trend is noted. The tumourgrowth rate is dramatically reduced, accompanied by downward adjustments in tumour volume change. 

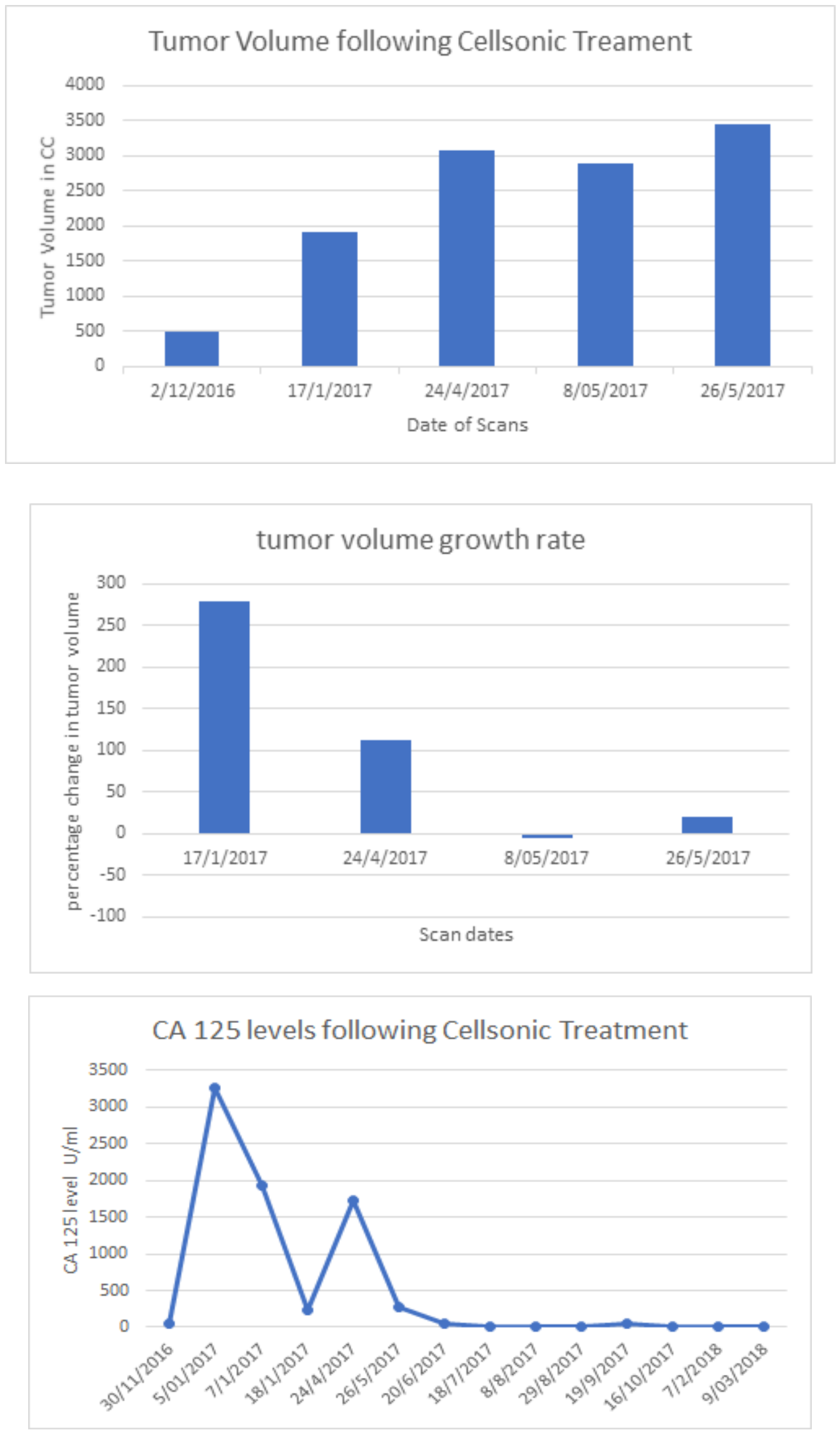
The Cellsonic VIPP treatments occurred in late December of 2016, just prior to second data point on the graph. We note that overall, the CA-125 levels have stabilized at below normal levels, which suggests the cancer is either in remission or even possibly absent. As of May 2021, the patient continues to thrive and enjoys a normal and active life following combination therapy utilizing the Cellsonic VIPP, even though the survival rate for stage 4 ovarian cancer is only $17 \%$. Although there initially is a pronounced rise in CA-125 levels following treatment, this may be explained as follows: endometriotic cyst fluids contain veryhigh concentrations of CA-125 but the thick walls of the endometriotic cyst prevents the large CA-125 glycoprotein molecules from reaching the peripheral circulation, although the block is not total. Some of the CA125 molecules leaking from the endometriotic cyst may be transferred through the peritoneum and the associated inflammatory reaction of the mesothelial cells of the peritoneum was probably the most important contributor to the presence of very high level of serum CA-125. It is likely that the mutated/cancer cells were ruptured by the VIPP pressure waves, resulting in 'spillage' from the cystic mass into the blood stream. The sudden and sharp rise in CA-125 levels following Cellsonic VIPP treatmentis not due to an intensified disease state. On the contrary, this spike is evidence of waste materials from de-natured cancer cells spilling into the bloodstream where they will be processed and removed via the kidneys. The data suggests that a detoxification/blood cleansing protocol might be a prudent adjunct to the treatment. This could be as simple as increased purified water intake.

Good news: I sent the draft of this article to Sundar for approval. He took it to Hema and she was pleased. Here is the picture Sundar took of Hema in her garden yesterday. She is happy and gratefulto CellSonic.

$5^{\text {th }}$ May 2021

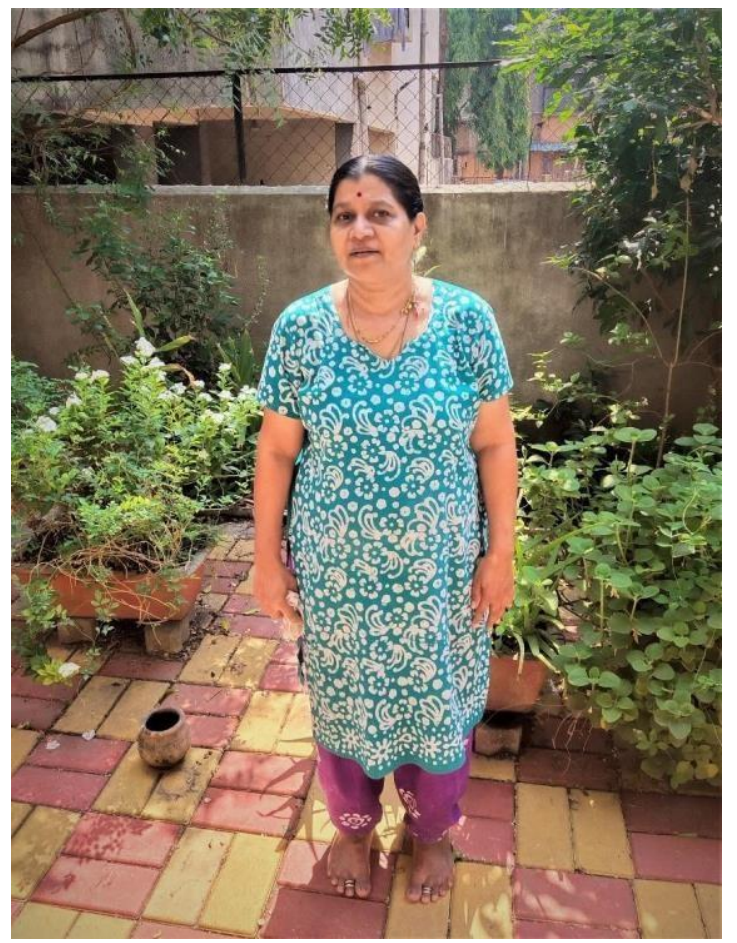

\section{References:}

1. Sundar Raman sundarpunein@ gmail.com

2. https://en.wikipedia.org/wiki/Permittivity

3. https://nathancrane.com/

4. Dr. Jerry Tennant, MD, MD(H), PScD
5. https://www.medicalandresearch.com/journals/view_article/112

6. http://www.scieniqpublishers.com/wpcontent/uploads/2020/09/The-hand-held-

7. thunderstorm.pdf

8. https://sapiensshield.com/ 